\title{
Effects of knife edge angle and speed on peak force and specific energy when cutting vegetables of diverse texture
}

\author{
Vishal Singh ${ }^{a^{*}}$, Madhusweta Das ${ }^{\mathrm{a}}$, And Susanta Kumar Das ${ }^{\mathrm{a}}$ \\ a Department of Agricultural and Food Engineering, Indian Institute of Technology, Kharagpur, \\ West-Bengal-721302, India \\ ${ }^{*}$ Corresponding author \\ vishalsinghiitkgp87@gmail.com \\ TEL: $+91-8093872582$
}

Received: 8 August 2014; Published online: 18 April 2016

\begin{abstract}
Cutting tool parameters such as edge-sharpness and speed of cut directly influence the shape of final samples and the required cutting force and specific energy for slicing or cutting operations. Cutting force and specific energy studies on different vegetables help to design the appropriate slicing or cutting devices. Peak cutting force and specific energy requirements for the transverse cutting of nine vegetables, differing in their textural characteristics of rind and flesh, were determined at cutting speeds of 20,30, $40 \mathrm{~mm} \mathrm{~min}^{-1}$ and single-cut knife-edge angles of 15, 20 and $25^{\circ}$ using a Universal Testing Machine. Low speed $\left(20 \mathrm{~mm} \mathrm{~min}^{-1}\right)$ cutting with a sharper knife-edge angle $\left(15^{\circ}\right)$ required less peak force and specific energy than that of high-speed cutting $\left(40 \mathrm{~mm} \mathrm{~min}^{-1}\right)$ with a wider knife-edge angle $\left(25^{\circ}\right)$. The vegetables with the maximum and minimum variation in the average peak cutting force were aubergine, at 79.05 (for knife speed $20 \mathrm{~mm} \mathrm{~min}^{-1}$ and edge angle $15^{\circ}$ ) to $285.1 \mathrm{~N}\left(40 \mathrm{~mm} \mathrm{~min}^{-1}\right.$ and $\left.25^{\circ}\right)$, and cucumber, at $11.61\left(20 \mathrm{~mm} \mathrm{~min}^{-1}\right.$ and $\left.15^{\circ}\right)$ to $21.41 \mathrm{~N}\left(40 \mathrm{~mm} \mathrm{~min}{ }^{-1}\right.$ and $\left.25^{\circ}\right)$, respectively. High speed $\left(40 \mathrm{~mm} \mathrm{~min}^{-1}\right)$, with a large knife-edge angle $\left(25^{\circ}\right)$, required the highest force and specific energy to cut the vegetables, however, low speed $\left(20 \mathrm{~mm} \mathrm{~min}^{-1}\right)$, with a small knife-edge angle $\left(15^{\circ}\right)$, is preferred. Effects of cutting speed and knife-edge angle on peak force and specific energy responses were found significant $(\mathrm{p}<0.05)$. Linear or quadratic regressions gave a good fit of these variables.
\end{abstract}

Keywords: Cutting force; Specific energy in cutting; Size reduction; Shaping of vegetables 


\author{
Abbreviations \\ F: $\quad$ Peak cutting force $(\mathrm{N})$ \\ SE: $\quad$ Specific energy $\left(\mathrm{N} \mathrm{m}^{-1}\right)$ \\ A: Knife angle \\ B: $\quad$ Knife speed $\left(\mathrm{mm} \mathrm{min}^{-1}\right)$ \\ s: $\quad$ Significant \\ ns: $\quad$ Non-significant \\ Wb: Wet basis (\%) \\ UTM: Universal Testing Machine
}

\section{Introduction}

Fruits and vegetables are usually peeled and cut into different shapes (e.g., cubes, thin slices, rings or shreds) to facilitate secondary processing. Materials of construction, sharpness, rigidity of cutting tools and cutting speed strongly influence the energy required, production rate and final surface of the sliced-pieces (Atkins, 2009; Blahovec, 2007). Cutting resistance is related to blade angle and sharpness of the knife blade (Bolin \& Huxsoll, 1991), as well as the various cutting action mechanisms and blade movements (such as rotary, vertical, horizontal, swiping, to and fro) and the relative movement of the object and cutting device (either object or knife is stationary). Cutting resistance also depends upon the characteristic intrinsic texture of the material (homogeneous or heterogeneous body).

Slicers used for cutting food materials operate with diverse direction of blade movements which are categorized as horizontal and vertical type (Jiang, 2013). Other cutting devices (such as laser cutters, water jet cutters and ultrasonic cutters) are not as versatile but are applied efficiently for some specific products. For example, an ultrasonic cutter is used for cutting fragile (cakes, pastry and bakery products), sticky and confectionary products (Arnold, Zahn, Legler, \& Rohm, 2011; Arnold, Leiteritz, Zahn, \& Rohm, 2009; Schneider, Zahn, \& Linke, 2002).

The slicing rate of vegetables decreases with increasing hardness and decreasing moisture content respectively (Yee, Mazlina, \& Tuah, 2012). In the case of some fruits, size reduction with the help of high speed cutting equipment is not suitable. The sharpness of the cutting tool has a significant impact on the shelf life of cut fresh vegetables (Brown, James, \& Purnell, 2005). Pears sliced with a sharpened knife retained a longer visual quality than those cut with a dull knife (Ciulicua \& Rus, 2012). The heterogeneous character of the fruit and vegetables under test has several factors such as presence of hard or soft rind, single or multiple seeds, fibrous or juicy flesh, as well as layers in the fleshy body. Extent of maturity and moisture content also need to be taken into account. Vegetables which have a moisture content less than $10 \%$ are categorized as brittle and frequently cause a cracked texture during slicing (Corrêa, Farinha, Oliveira, Campos, \& Finger, 2010). Vegetables of high moisture content facilitate precise slicing (slicing with uniform shape and size), without any texture deformation, because the moisture behaves like a lubricant during slicing and reduces the friction (Gamble \& Rice, 1988). Firmness varies with the size of the fruits, and generally smaller fruits are harder than large ones (Gorny, Gil, \& Kader, 1998). The maximum cutting force is higher for the inner part (such as xylem and phloem) than for the upper layers in the case of carrot (Lurie \& Crisosto, 2005). The force required to penetrate the carrot increases with increasing elastic behaviour during storage (McCarthy, Hussey, \& Gilchrist, 2007). Whilst there is extensive documentation on the properties of foods and food products, data related to the cutting force of different vegetables, especially of Indian origin, is scarce, even though such data is important in the design of cutters. Little work has been carried out on the energy involved for cutting fibrous food materials (McGorry, Dowd, \& Dempsey, 2003). Limited published literature on specific energy in cutting of fruits and vegetables is available (Mitcham, Cantwell, \& Kader, 1996). Different food cutting devices have 
been designed empirically based on the physical properties of food materials (Saravacos \& Kostaropoulos, 2002). The specific energy for cutting a few vegetables has been presented elsewhere (Saravacos \& Maroulis, 2011).

A study of the cutting force requirements of vegetables, with different characteristics of flesh and rind, that is, homogeneous and heterogeneous texture and apparently hard and soft layers of endocarp (case of seed containing vegetables), could be utilized for the design of cutting systems or devices, with optimum energy requirements. Variation of knife speed and cutting angle within this study of cutting force and specific energy requirements for vegetables with a diverse texture would facilitate the selection of appropriate existing cutting devices.

\section{Materials and Methods}

\subsection{Vegetables of different texture and instrument used in experiment}

Nine vegetables of different textures were chosen for this study. These are categorised as homogeneous texture (potato, radish, and carrot), single layer texture (bell pepper), multilayer texture (onion), heterogeneous texture with flesh and seeds (pointed gourd and bitter gourd), heterogeneous texture with soft seeds (cucumber) and soft and spongy texture (aubergine). Figure 1 shows the pictures of these vegetables. Freshly harvested, healthy (without any visible defects) and tender vegetables of uniform size were obtained from a local farm. Moisture content of the respective vegetables was measured by oven drying method (AOAC, 1999), and varied between 78.52 to $93.59 \%$ (wb). Diameter values (major, intermediate and minor) of the vegetables were also measured (Table 1). Standard deviation and coefficient of variation (C.V.) were calculated for all moisture content and diameter values (Table 1). All collected vegetables were washed thoroughly and blotted for removal of surface moisture before being subject to cutting using an Universal Testing Machine (Instron, UK, Model no 1011, load cell type LVDT, load range $500 \mathrm{~N}$ ).
A special cutting fixture was used for all these cutting tests.

\subsection{Cutting knives}

The knives of different cutting edge angles (single cut) were fabricated in the workshop (instrument manufacturing and repairing centre) of the Indian Institute of Technology, Kharagpur using stainless steel (Grade 304). The dimensions of these knives (length $-145 \mathrm{~mm}$ and width -75 $\mathrm{mm}$ ) were chosen according to the provision kept in the fixture assembly of the Universal testing machine (UTM). The thickness of these knives was $0.952 \mathrm{~mm}$. Figure 2 shows the schematic of the cutting-blade. The blades were perfectly straight, with a smooth surface edge, so that they did not touch the guided channel in the fixture during its downward movement. Three cuttingedge angles, 15, 20 and $25^{\circ}$ were used in this study. Sharpening the required cutting-edge angle blades was carried out with a rotary grinding wheel for a smooth finish of the cutting edge. For every set of experiments, the blades were resharpened to avoid error due to a blunt face of the cutting edge.

\subsection{Cutting fixture in the universal testing machine}

The universal testing machine used in this study consists of a cross-head attached to a load-cell (LVDT type), with a lowest resolution of 0.125 N. A desired cross-head speed ranging between $1 \mathrm{~mm} / \mathrm{min}$ to $500 \mathrm{~mm} / \mathrm{min}$ could be set. The cutting operation was carried out under compression mode. A special fixture for movement of the knife was installed in this UTM (Figure 3). The installed knife for a particular test was allowed to move up and down (with perfect vertical alignment) along a guided channel to give least or almost no friction. A no-load run of the knife was carried out to measure the force due to friction in the channel. This value (error) was adjusted with each measurement.

Then the knife was allowed to move down at desired speed. Force and depth of cut (travel of knife) was recorded until the knife completely cut the test vegetable transversely into two halves. 
Cutting force and specific energy for vegetables |25

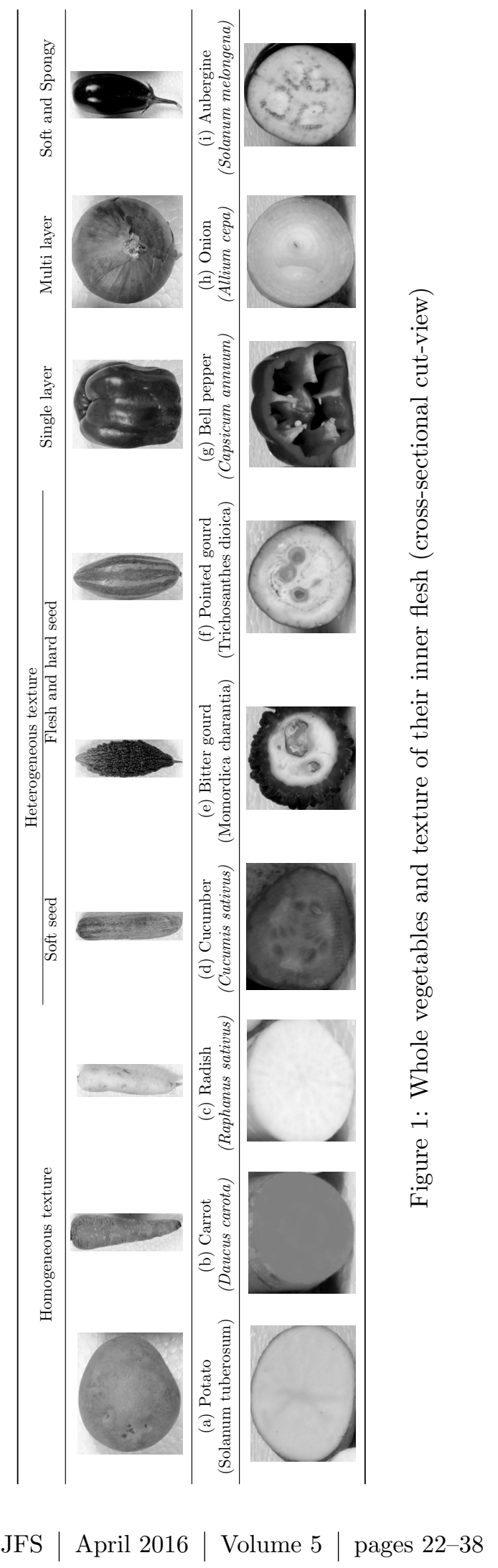


$26 \mid$ Singh et al.

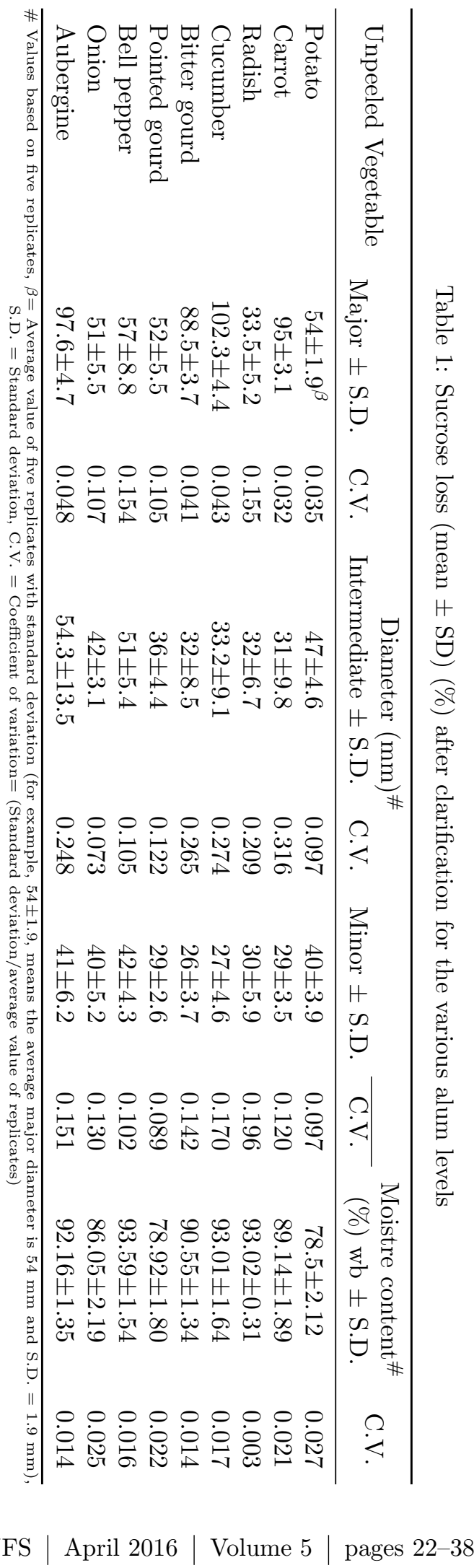


Cutting force and specific energy for vegetables $\mid 27$

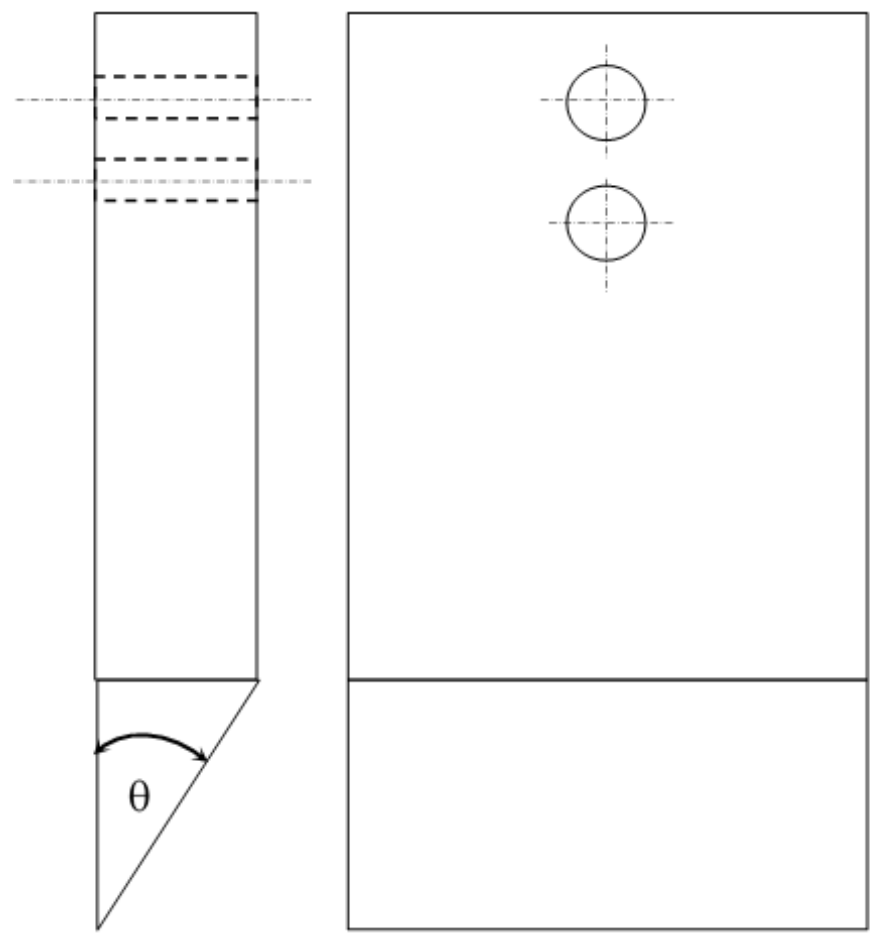

Figure 2: Schematic of the knife blade made with Grade-304 stainless steel (Side and front view)

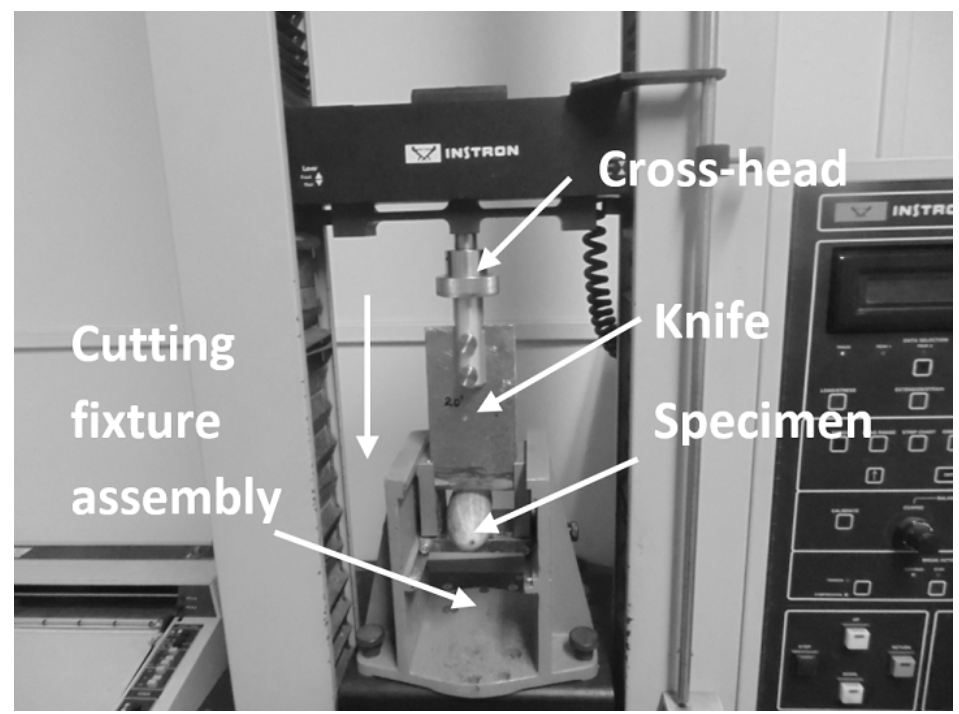

Figure 3: Knife movement within the universal testing machine (Instron, UK, Model no 1011, load cell type LVDT, load range $500 \mathrm{~N}$ ) 
Three cross-head speeds, 20, 30 and $40 \mathrm{~mm}$ $\mathrm{min}^{-1}$, were set for each of the vegetables. The force-deformation profiles were recorded using an $\mathrm{x}-\mathrm{y}$ chart recorder, coupled with two independent variables taken on the UTM, such as knife-edge angle and cutting speed (coupled $\mathrm{x}-\mathrm{y}$ chart with UTM automatically generate the graphs for variation of cutting force with increasing depth of cut), for the nine vegetables, with five replications of each. Peak cutting force and total energy (area under force-depth of cut curve) were read from the digital display of the machine. All these experiments were carried out separately, taking a fresh vegetable each time.

\subsection{Average diameter and specific energy in cutting}

The cross-wise diameters of each specimen were measured using a dial mounted slide calliper (Model no-D30TN, Mitutoyo Corporation, Japan, least count $0.02 \mathrm{~mm}$ and measuring range 0-300 $\mathrm{mm}$ ), and the area of cut (transverse section) was then calculated. Figure 1 shows the transverse section of each vegetable. Specific energy for cutting (total energy/area of cut) for each specimen was estimated (in $\mathrm{J} \mathrm{m}^{-2}$ equivalent to $\mathrm{N} \mathrm{m}^{-1}$ ), and average values with standard deviation were reported.

\subsection{Statistical analyses}

General factorial design of experiments was followed using software (Design expert version 7.0, Stat - Ease INC., 2009, USA). Nine tests for each vegetable for three knife angles $\left(15^{\circ}, 20^{\circ}\right.$ and $25^{\circ}$ ) and three speeds (20,30 and $40 \mathrm{~mm}$ $\min ^{-1}$ ), along with five replications were carried out. Significance of the effects of all the independent variables on cutting force and specific energy were evaluated using analysis of variance (ANOVA).

To find out the effect of independent variables $\left(\mathrm{X}_{1}\right.$ and $\left.\mathrm{X}_{2}\right)$ on the dependent variable (responses, $\mathrm{Y})$, the following quadratic regression equation was fitted (Equation 1)

$$
\begin{aligned}
Y= & b_{0}+b_{1} X_{1}+b_{2} X_{2}+b_{3} X_{3}+b_{4} X_{4}+\ldots \\
& +b_{12} X_{1} X_{2}+b_{13} X_{1} X_{3}+b_{14} X_{1} X_{4}+\ldots \\
& +b_{23} X_{2} X_{3}+b_{11} X_{1}^{2}+b_{22} X_{2}^{2}+\ldots \\
& +b_{33} X_{3}^{2}+b_{44} X_{4}^{2}+\ldots
\end{aligned}
$$

Regression equation 1 has been used for relating the different variables for knife speed and cutting force with the help of the same software. A and $\mathrm{B}$ are knife speed and knife-edge angle, respectively, and $\mathrm{Y}$ is the response (peak cutting force or specific energy) expressed in Equation 2

$Y=b_{0}+b_{1} A+b_{2} B+b_{12} A B+b_{11} A^{2}+b_{22} B^{2}+\ldots$

Where b-terms $\left(b_{0}, b_{2}, b_{12}, b_{11}\right.$ and $\left.b_{22}\right)$ are coefficients of the regression equation.

\section{Results and Discussion}

\subsection{Cutting characteristics of vegetables}

Typical force and deformation (depth of cut) characteristics of vegetables (one from each vegetable) on $\mathrm{x}-\mathrm{y}$ charts (automatically generated due to movement of knife coupled with UTM) are presented in Figure $4(\mathrm{a}-\mathrm{i})$. The nature of the curves obtained at different knife edge angles $\left(15,20\right.$ and $\left.25^{\circ}\right)$ and cutting speeds (20, 30 and $40 \mathrm{~mm} \mathrm{~min}^{-1}$ ) were almost similar.

Vegetables, like potato, carrot and radish, showed a steady increase in cutting force (Figures $4 \mathrm{a}-\mathrm{c}$ ) that attained a peak value followed by its steady decrease as the depth of cut was increased. The entire curve could be divided into two halves that appeared to be almost mirror images with respect to a point corresponding to the peak force. This type of increase in force, up to around a mid point, and decrease thereafter is attributed to increase and decrease in shearing area (for cylindrical shape body) during penetration of the blade. There was least fluctuation (undulation) in the curve, indicating homogeneity in texture.

Force versus depth of cut curve for cucumber (Figures 4d) showed a small rise in force initially while the knife penetrated the rind. With 
the process of cutting, the force remained almost invariant (with little increase in magnitude but without much ripple) till the end of this operation. It is apparent from comparison of this particular nature of curve with those of potato, carrot and radish that, cucumber has homogeneous texture. Furthermore, even with an increase in the area of the cut, the force did not increase much, indicating a soft core texture for cucumber.

Vegetables with multiple seeds, such as bitter gourd and pointed gourd, showed typical forcedepth of cut characteristics having peaks and ripples (Figures 4e and f). Bitter gourd has a thick and tough rind. Force increased steeply, mostly due to initial compression of the soft core, followed by penetration of knife into the rind and central flesh. The last part of this curve also showed a rise in force, indicating again the tough nature of the rind. The central part with ripples is due to the presence of seeds and soft flesh; seeds are harder than the flesh. The nature of the curve for pointed gourd also has ripples due to the presence of seeds and soft flesh inside, but its rind is not as tough as that of bitter gourd. Penetration of the blade was smooth, and cutting could be initiated without much deformation or compression of the sample.

Bell pepper, with its single layer and inside hollow texture, showed much compression initially (steep rise in force with pseudo depth of cutting) before the actual cutting of the flesh (only thick rind) occurred (Figures 4g). A second peak with much lower magnitude of force indicated the soft central core of the vegetable holding seeds (Figure $4 \mathrm{~g}$ ). The final steep rise in force was attributed to compression of the thick rind against the hard cutting platform, along with its cutting. Onion, with a multiple layer texture, showed a slow increase in cutting force with increase in depth of cut (Figure 4h). The centre part of this curve contained multiple ripples. The peak parts of these ripples indicate progressive cutting of layers, and the falling parts indicate small gaps in between the layers. Similar to vegetables with homogeneous texture, this curve also shows symmetrical halves, indicating uniform cutting force of respective layers and with a single peak that depends on the area of cut for the vegetable. Aubergine showed a different type of force-depth of cut characteristics (Figure 4i); initial sharp and almost linear increase in force to a very high value (compared to any vegetables chosen in this study) with considerable deformation of the vegetable but without penetration of the knife into the flesh. It was followed by almost vertical fall in force to a very low value that continued until the vegetable was completely cut into halves. It indicates the tough nature of Aubergine skin and very soft texture of its flesh to accommodate the force with its own deformation.

\subsection{Effect of cutting speed and knife-edge angle on peak cutting force}

Average cutting forces for different vegetables are given in Table 2. All these vegetables showed apparent increase in peak force with increase in cutting speed and knife-edge angles. The magnitude of these peak-cutting forces varied with the nature of vegetable. Bitter gourd and Aubergine showed rapid increase in peak cutting force, with increase in either cutting speed or knife-edge angle, compared to other vegetables. Potato, carrot and radish showed average peak forces varied from 43.68 to $61.49,47.90$ to 67.59 and 36.84 to $58.38 \mathrm{~N}$, respectively. Onion showed variation of peak cutting force close to these homogeneous texture vegetables (46.36 to $70.93 \mathrm{~N})$. Average values for bell pepper and pointed gourd varied respectively as 32.17 to 51.02 and 24.62 to $50.32 \mathrm{~N}$. Variation of this force for bitter gourd and Aubergine were maximum, with values from 51.50 to 91.05 and 79.05 to $285.1 \mathrm{~N}$, respectively (Table 2). Cucumber showed least variation (11.61 to $21.41 \mathrm{~N}$ ). In all these vegetables, it is apparent that high speed $\left(40 \mathrm{~mm} \mathrm{~min}{ }^{-1}\right)$ and large knife-edge angle $\left(25^{\circ}\right)$ required highest force, and low speed cutting is preferred.

Linear regression equations (Table 3) were obtained for peak cutting force for carrot, radish, pointed gourd, bell pepper, onion and aubergine (only $b_{0}, b_{1}$ and $b_{2}$ regression coefficient and single terms $\mathrm{A}$ and $\mathrm{B}$ are obtained) and polynomial regression equations were fitted for vegetables like Potato, Cucumber, Bitter gourd $\left(b_{0}, b_{1}\right.$, $\mathrm{b}_{2}, \mathrm{~b}_{12}, \mathrm{~b}_{11}, \mathrm{~b}_{22}$ regression coefficient and single, interaction and quadratic terms are obtained). 


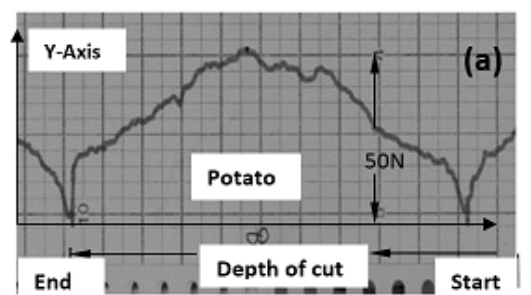

(a) Knife angle- $15^{\circ}$ and Cutting speed $-30 \mathrm{~mm} \mathrm{~min}^{-1}$

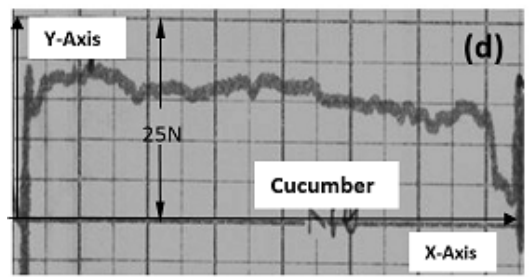

(d) Knife angle- $20^{\circ}$ and Cutting speed $-20 \mathrm{~mm} \mathrm{~min}^{-1}$

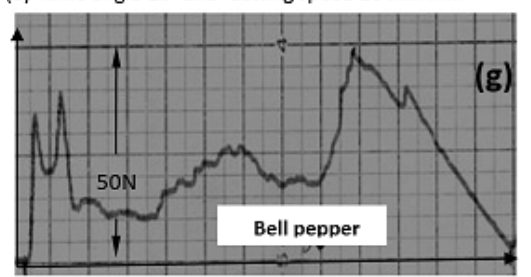

(g) Knife angle- $20^{0}$ and Cutting speed $-40 \mathrm{~mm} \mathrm{~min}^{-1}$

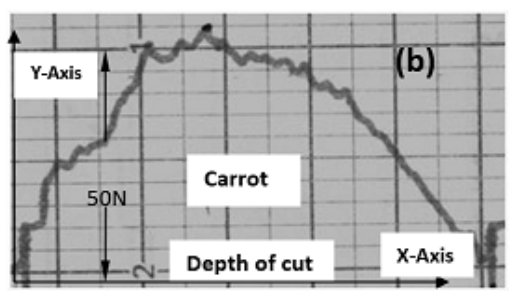

(b) ) Knife angle $-20^{\circ}$ and Cutting speed $-30 \mathrm{~mm} \mathrm{~min}^{-1}$

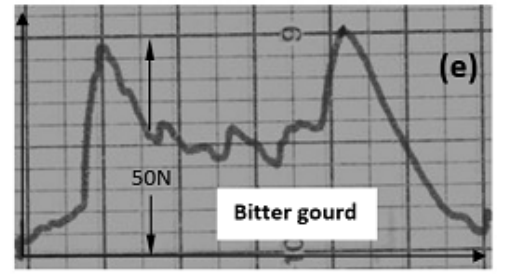

(e) Knife angle- $-15^{\circ}$ and Cutting speed-30 $\mathrm{mm} \mathrm{min}^{-1}$

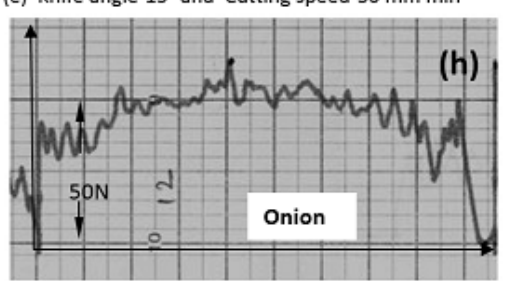

(h) Knife angle- $15^{\circ}$ and Cutting speed $-30 \mathrm{~mm} \mathrm{~min}^{-1}$

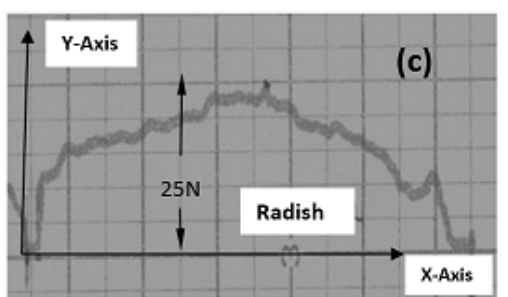

(c) Knife angle $-20^{\circ}$ and Cutting speed $-30 \mathrm{~mm} \mathrm{~min}^{-1}$

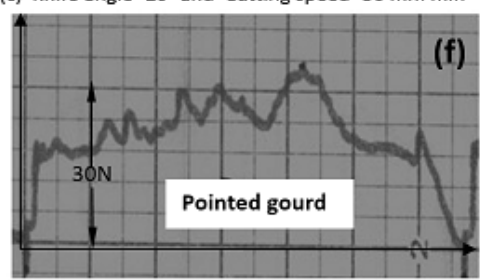

(f) Knife angle-20 and Cutting speed-30 $\mathrm{mm} \mathrm{min}^{-1}$

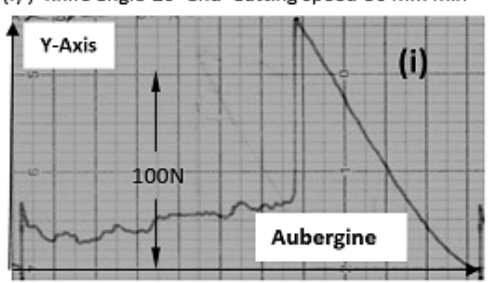

(i) Knife angle- $15^{0}$ and Cutting speed-30 $\mathrm{mm} \mathrm{min}^{-1}$

Figure 4: Typical representation of cutting force and deformation (depth of cut) characteristics of vegetables, Y-Axis-Cutting Force and X-Axis-Depth of cut. All these graphs are generated by UTM for individual vegetables (force-deformation graphs obtained on an x-y chart for a fixed knife movement within the UTM)

General factorial design (Design expert version 7.0) automatically produced the values of regression coefficients associated with single (A and $B)$, interaction $(\mathrm{A} \times \mathrm{B})$ and square $\left(\mathrm{A}^{2}\right.$ and $\left.\mathrm{B}^{2}\right)$ terms for cutting force of each vegetable with significance level (Table 3). For potato, values of the regression coefficient for the fitted model (regression equation) were generated where all the respective coefficient values were significant except b12 (coefficient of $\mathrm{A} \times \mathrm{B}$ ) and $\mathrm{b}_{22}$ (coefficient of $\mathrm{B}^{2}$ ) (Table 3).

Increasing the value of knife speed and knife angle increased the peak force requirements to cut the vegetables. To facilitate the relative study of the effect of two significant variables (knife angle and speed) simultaneously on the peak cutting force (response), 3-D graphical representation was convenient (Figure 5).

Figure 5 shows the cutting force increased with knife angle and speed in case of carrot, radish, pointed gourd, bell pepper and onion with a linear trend (following linear fit equation as shown in table Table 3) but for potato, cucumber and bitter gourd a polynomial trend (following polynomial fit equation as presented in table 3) was observed.

The effects of knife speed and knife-edge angle on peak cutting force have been evaluated for each of these vegetables using two-way analysis of variance at the $95 \%$ confidence level $(p<0.05)$. A significant effect with these independent variables on the response (peak force) and values of $\mathrm{R}^{2}, \mathrm{R}^{2}$ (Adj.), $\mathrm{R}^{2}$ (Pred.) and C.V. for different vegetables are summarised in Table 3 . 
Cutting force and specific energy for vegetables |31
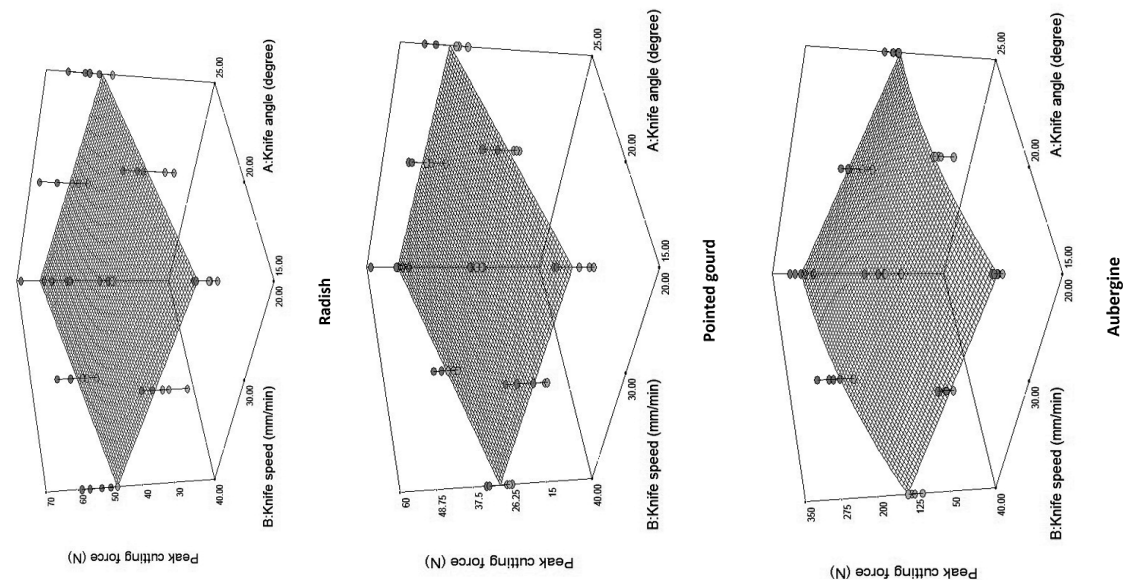

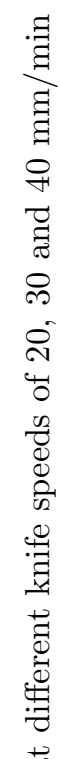
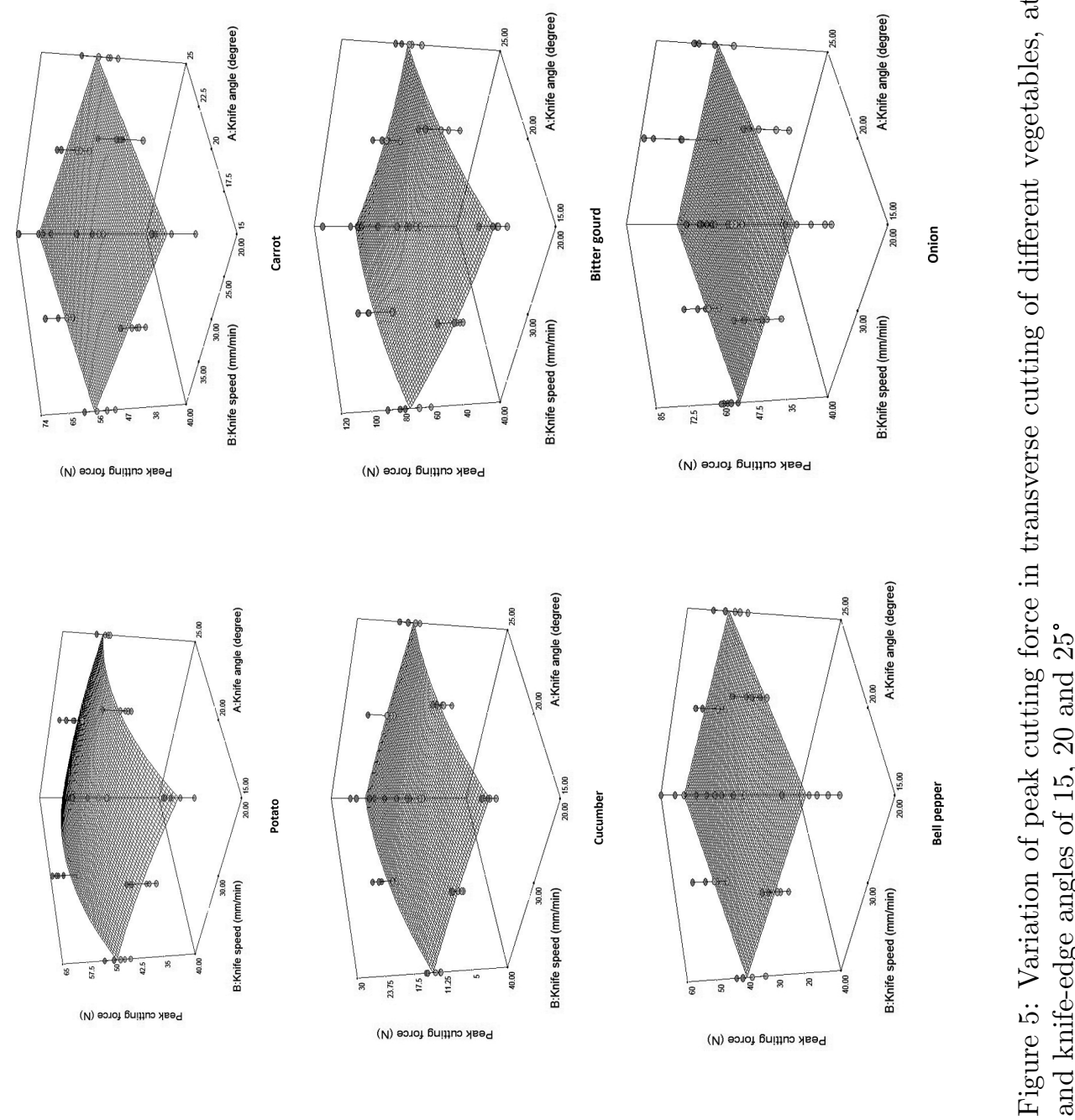

IJFS | April 2016 | Volume 5 | pages 22-38 
32 Singh et al.

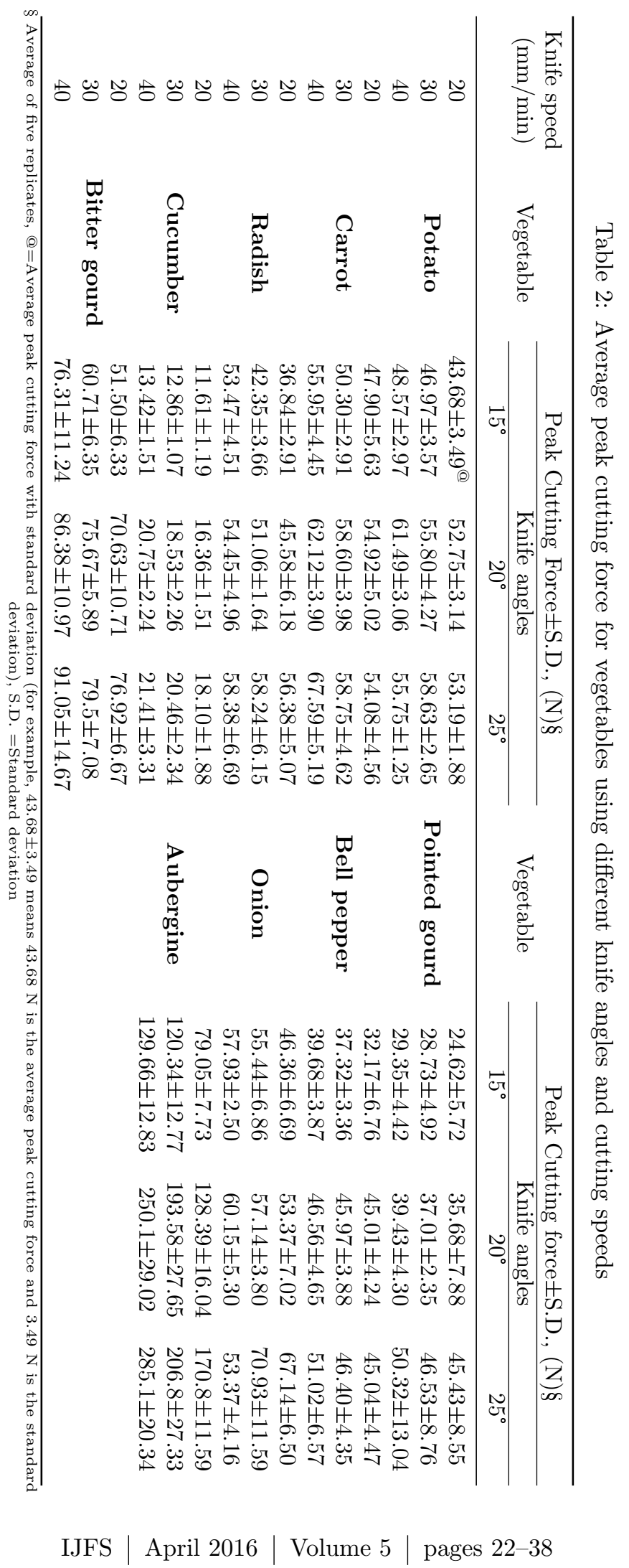


Cutting force and specific energy for vegetables |33

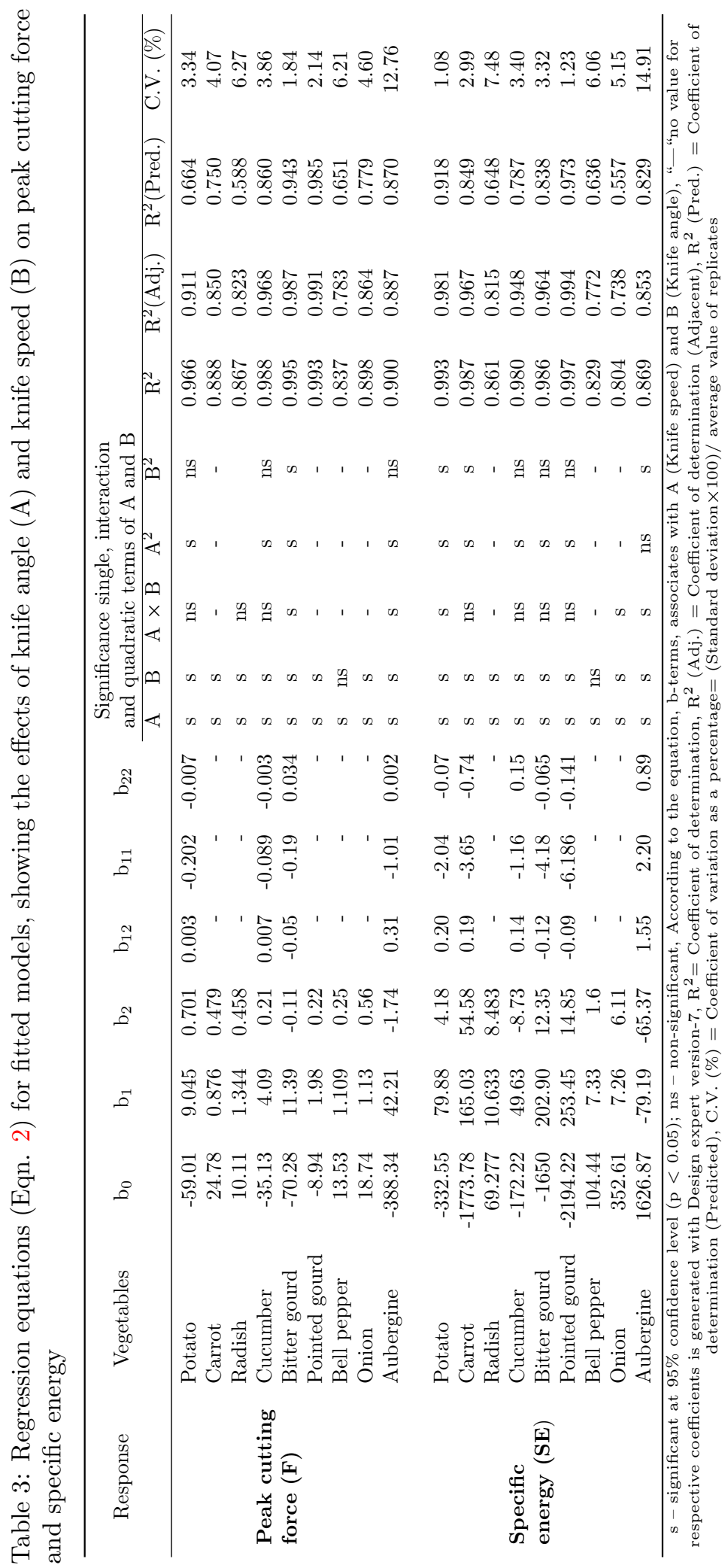

IJFS | April 2016 | Volume $5 \mid$ pages 22-38 


\subsection{Effect of speed and knife-edge angle on specific energy in cutting}

Table 4 gives the average specific energy values of all vegetables at different cutting speed and knife-edge angles. For all these vegetables, a sharp change in specific energy occurred when the knife-edge angle changed from $15-20^{\circ}$ but such a change in specific energy was not observed between 20 and $25^{\circ}$. However, for pointed gourd, a decreasing trend at higher knife-edge angle was noticed. In the case of aubergine, this change in specific energy was consistent with an increase in knife angle, and the range was highest (450 to $1340 \mathrm{~N} \mathrm{~m}^{-1}$ ). High speed cutting with a large knife-edge angle consumed more energy, with compression before cutting the thin skin of aubergine. Among the three vegetables with a homogeneous texture, the difference between potato and radish was found to be least. Corresponding specific energy values varied from 525 to $670 \mathrm{~N} \mathrm{~m}^{-1}$ and 350 to $643 \mathrm{~N} \mathrm{~m}^{-1}$. Carrot appeared to be much harder with a variation in specific energy from 722 to $1250 \mathrm{~N} \mathrm{~m}^{-1}$. Specific energy values of cucumber (238 to $373 \mathrm{~N} \mathrm{~m}^{-1}$ ) and bell pepper (232 to $346 \mathrm{~N} \mathrm{~m}^{-1}$ ) were quite similar to each other at all speeds and angles. In the case of onion (526 to $744 \mathrm{~N} \mathrm{~m}^{-1}$ ), specific energy was found to be higher than potato. A large variation in specific energy for bitter gourd (620 to $1100 \mathrm{~N} \mathrm{~m}^{-1}$ ) might be attributed to its thick tough rind and hard seeds.

Regression equations for all the vegetables and effects of independent variables on specific energy are presented in Table 3.

Figure 6 shows a comprehensive pictorial presentation of linear and quardratic variations of specific energy with respect to knife speed and knife-edge angle, corroborated with corresponding regression equations. Specific energy increases with increased value of knife speed and knife angle. 3-Dimensional graphical representation is used to study the effect of both variables (knife angle and speed) simultaneously on the response (specific energy) due to the significant effect of these two variables. It was also observed that the increment in specific energy was more prominent for knife angle than knife speed (Fig- ure 6).

The specific energy increased with increasing knife angle and speed for radish, bell pepper, onion and aubergine with a linear trend (following linear fit equation as shown in table 3) but for potato, carrot, cucumber, bitter gourd and pointed gourd a polynomial trend (following polynomial fit equation as presented in table 3 ) was observed (Figure 6).

Table 3 shows the linear equations for response (specific energy) for radish, bell pepper, onion and aubergine (only $\mathrm{b}_{0}, \mathrm{~b}_{1}$ and $\mathrm{b}_{2}$ regression coefficient with single terms $\mathrm{A}$ and $\mathrm{B}$ are generated with design expert model) and polynomial regression equations fitted for vegetables like Potato, Carrot, Cucumber, Bitter gourd and pointed gourd $\left(b_{0}, b_{1}, b_{2}, b_{12}, b_{11}, b_{22}\right.$ regression coefficient with single, interaction and quadratic terms are generated).

The significant or non-significant effects of different knife speed and knife-edge angle on specific energy for each vegetable were estimated using analysis of variance (ANOVA) at $\mathrm{p}<0.05$. The significant effect with these independent variables on response (specific energy) and values of $\mathrm{R}^{2}, \mathrm{R}^{2}$ (Adj.), $\mathrm{R}^{2}$ (Pred.) and C.V. for different vegetables are summarised in Table 3 .

\section{Conclusions}

Th peak force and specific energy required to cut vegetables depends upon the texture of the rind and flesh, and their homogeniety. Cutting speed and knife-edge angle significantly influence the peak force and specific energy. Low speed cutting with a sharp angle cutter is favoured for low peak cutting force and specific energy. Vegetables with soft texture require high peak force and specific enegry, with a vertical cutting mechanism. Variation of the cutting force was maximum $(285.1 \mathrm{~N}$ for $40 \mathrm{~mm} \mathrm{~min}^{-1}$ and $25^{\circ}$ ) and minimum (11.61 for $20 \mathrm{~mm} \mathrm{~min}^{-1}$ and $15^{\circ}$ ) for aubergine and cucumber respectively. High speed $\left(40 \mathrm{~mm} \mathrm{~min}^{-1}\right)$ and large knife-edge angle $\left(25^{\circ}\right)$ required highest specific energy and force to cut the vegetables; however, it becomes counterproductive for onion (maximum cutting force obtained $70.93 \mathrm{~N}$ at 30 $\mathrm{mm} \min ^{-1}$ for $25^{\circ}$ ) due to irregularities in several layers. A combination of $20 \mathrm{~mm} \mathrm{~min}^{-1}$ knife 
Cutting force and specific energy for vegetables |35
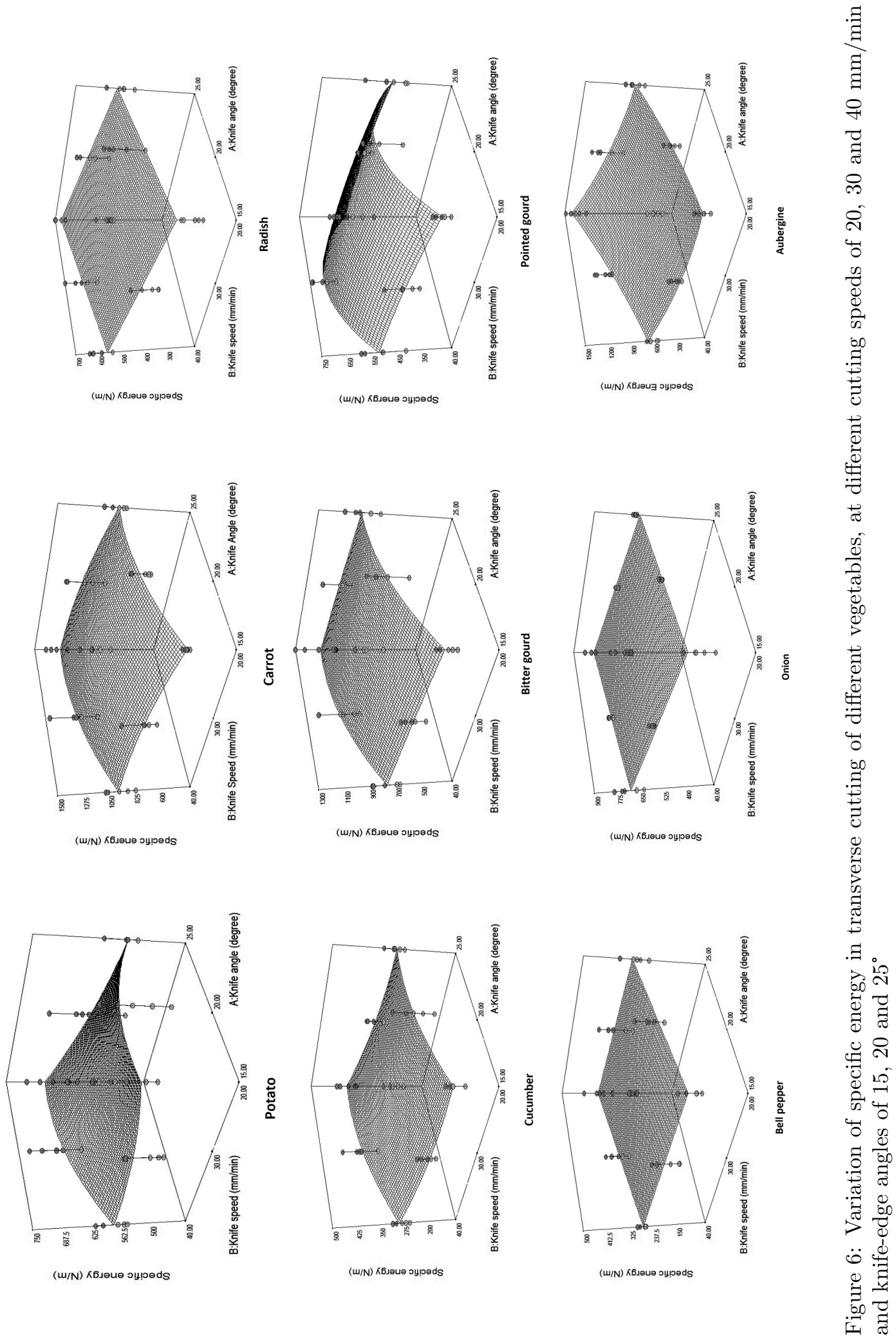

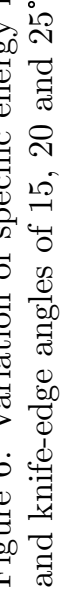

IJFS | April 2016 | Volume 5 | pages 22-38 
36 | Singh et al.

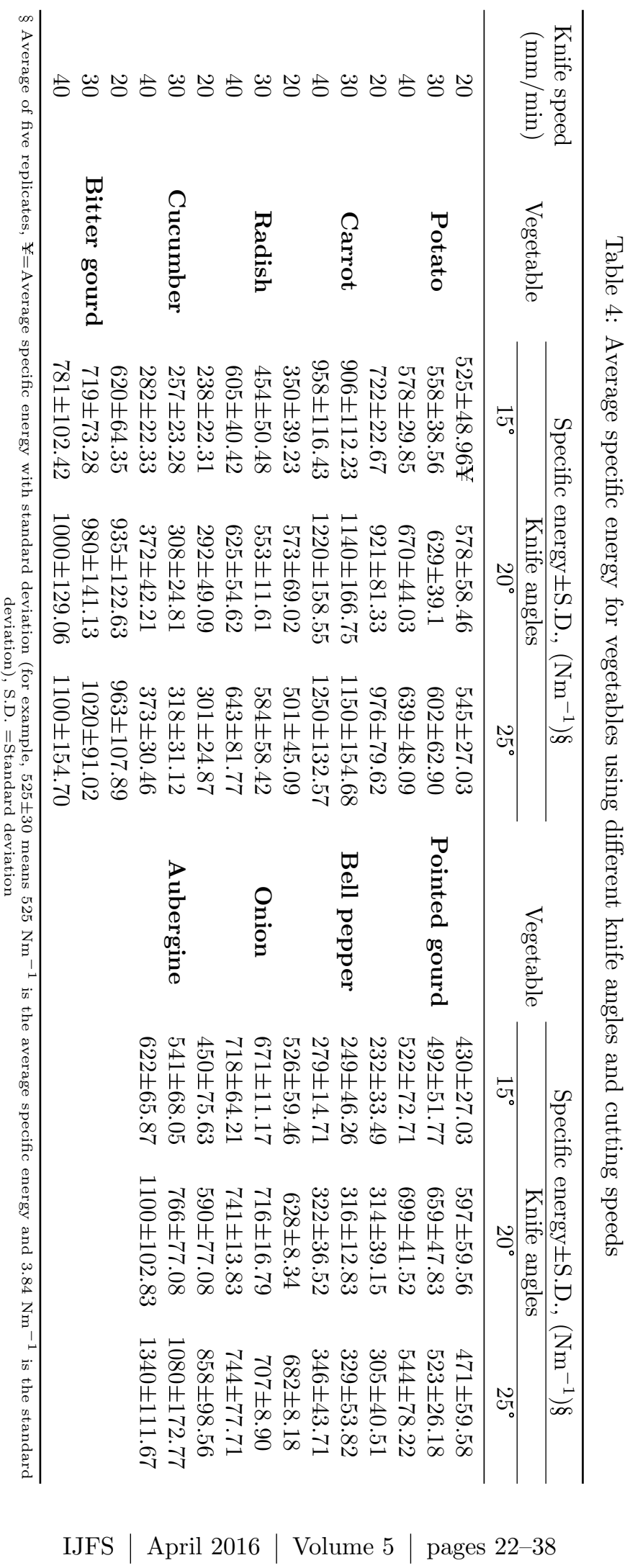


speed and edge angle of $15^{\circ}$ provides least cuting force as well as specific energy. In the case of aubergine, this change in specific energy was consistent with the increase in knife angle, and the range was highest ( 450 to $1340 \mathrm{~N} \mathrm{~m}^{-1}$ ). The specific energy value of bell pepper (232 to 346 $\mathrm{N} \mathrm{m}^{-1}$ ) was minimum. A swiping mechanism of cutting may be suitable to reduce this force and energy. Good correlations among the variables could be used to predict peak cutting force and specific energy.

\section{References}

AOAC. (1999). Official methods of analysis (16th ed.) AOAC International. Maryland: Gaithersburg.

Arnold, G., Leiteritz, L., Zahn, S., \& Rohm, H. (2009). Ultrasonic cutting of cheese: composition affects cutting work reduction and energy demand. International Dairy Journal, 19(5), 314-320. doi:10.1016/j.idairyj. 2008.11.007

Arnold, G., Zahn, S., Legler, A., \& Rohm, H. (2011). Ultrasonic cutting of foods with inclined moving blades. Journal of Food Engineering, 103(4), 394-400. doi:10.1016/j. jfoodeng.2010.11.009

Atkins, T. (2009). The science and engineering of cutting: the mechanics and processes of separating, scratching and puncturing biomaterials, metals and non-metals. Butterworth-Heinemann.

Blahovec, J. (2007). Role of water content in food and product texture. International Agrophysics, 21(3), 209-215.

Bolin, H. R. \& Huxsoll, C. C. (1991). Effect of preparation procedures and storage parameters on quality retention of salad-cut lettuce. Journal of Food Science, 56(1), 6067. doi:10.1111/j.1365-2621.1991.tb07975. $\mathrm{x}$

Brown, T., James, S. J., \& Purnell, G. L. (2005). Cutting forces in foods: experimental measurements. Journal of Food Engineering, 70(2), 165-170. doi:10.1016/j.jfoodeng . 2004.09.022

Ciulicua, l. G. \& Rus, F. (2012). Experimental regarding the determination of the optimum cutting angle using a single edged knife. Bulletin of the Transilvania University of Brasov, Series II. Forestry, Wood Industry, Agricultural Food Engineering, (1).

Corrêa, P. C., Farinha, L. R. L., Oliveira, G. H. H., Campos, S. C., \& Finger, F. L. (2010). Texture evaluation affected by physical characteristics of carrots during storage. In CIGR XVII. World Congress of the International Commission of Agricultural and Biosystems Engineering. Retrieved from http://www.csbe-scgab.ca/ docs/meetings/2010/CSBE101115.pdf

Gamble, M. H. \& Rice, P. (1988). The effect of slice thickness on potato crisp yield and composition. Journal of Food Engineering, 8(1), 31-46. doi:10.1016/0260-8774(88) 90034-9

Gorny, J. R., Gil, M. I., \& Kader, A. A. (1998). Postharvest physiology and quality maintenance of fresh-cut pears. In R. Bieleski, W. Laing, \& C. Clark (Eds.), Postharvest'96 proceedings of the international postharvest science conference (Vol. 464, pp. 231-236). Acta Horticulturae. International Postharvest Science Conference, Postharvest 96, TAUPO, NEW ZEALAND, AUG 04-09, 1996.

Jiang, X. (2013). Design and research on household food slicer. Advance Journal of Food Science and Technology, 5(10), 1296-1300. Retrieved from http:// maxwellsci.com / print/ajfst/v5-1296-1300.pdf

Lurie, S. \& Crisosto, C. H. (2005, September). Chilling injury in peach and nectarine. Postharvest Biology and Technology, 37(3), 195-208. doi:10.1016/j.postharvbio. 2005. 04.012

McCarthy, C. T., Hussey, M., \& Gilchrist, M. D. (2007). On the sharpness of straight edge blades in cutting soft solids: part i - indentation experiments. Engineering Fracture Mechanics, 74 (14), 2205-2224. doi:10. 1016/j.engfracmech.2006.10.015

McGorry, R. W., Dowd, P. C., \& Dempsey, P. G. (2003). Cutting moments and grip forces in meat cutting operations and the effect of knife sharpness. Applied Ergonomics, 34(4), 375-382. doi:10.1016/ S0003-6870(03)00041-3 
Mitcham, B., Cantwell, M., \& Kader, A. (1996). Methods for determining quality of fresh commodities. Perishables handling newsletter, 85, 1-5. Retrieved from http: / / ucce. ucdavis . edu / files / datastore / 23449.pdf

Saravacos, G. D. \& Kostaropoulos, A. E. (2002). Handbook of food processing equipment. Springer Science \& Business Media.

Saravacos, G. D. \& Maroulis, Z. B. (2011). Food process engineering operations. CRC Press.

Schneider, Y., Zahn, S., \& Linke, L. (2002). Qualitative process evaluation for ultrasonic cutting of food. Engineering in Life Sciences, 2(6), 153-157. doi:10.1002/16182863(200206) 2:6〈153::AID-ELSC153〉3.0. $\mathrm{CO} ; 2-\mathrm{Z}$

Yee, L. C., Mazlina, M. K. S., \& Tuah, B. T. H. (2012). Relationship between selected properties of starchy vegetables on grating and slicing production rate. American Journal of Agricultural and Biological Sciences, 7(2), 232-238. doi:10.3844/ ajabssp.2012.232.238 